\title{
A aplicabilidade do Princípio da Proibição do Retrocesso Social como meio de garantia constitucional ao direito à saúde
}

The applicability of the Principle of Prohibition of the Social Regression as a means of guaranteeing the constitutional right to health

La aplicabilidad del Principio de la Prohibición del Retroceso Social como medio de garantía constitucional al derecho a la salud

Kalini Vasconcelos Braz ${ }^{1}$

RESUMO. Introdução: o presente artigo se propôs a analisar possíveis retrocessos sociais advindos da Emenda Constitucional no 86, de 2015, e da Lei no 13.097, de 2015. Metodologia: tratou-se de pesquisa quantiqualitativa, de caráter descritivo analítico, realizada por meio de pesquisa documental. De forma complementar, foi realizada revisão bibliográfica sobre o princípio da proibição do retrocesso social. Resultados: concluiu pela existência de retrocesso social em ambos os textos legais, uma vez que as mudanças legislativas propostas conduzem à fragilização do direito à saúde e do Sistema Único de Saúde (SUS), notadamente no aspecto do financiamento que pode afetar a sua própria sustentabilidade. Quanto à Lei no 13.097, de 2015 verificou-se retrocesso no art. 142, que ao permitir a participação direta ou indireta do capital estrangeiro em todas as atividades de assistência à saúde, até mesmo em instituições filantrópicas, pode propiciar a expansão do setor privado e consequente mercantilização do direito à saúde acentuando as desigualdades de acesso ao sistema de saúde. Já a Emenda Constitucional no 86, de 2015, que inclui uma nova base de cálculo para a aplicação do governo federal na saúde, verifica-se o retrocesso social ao não observar o caráter progressivo de investimentos em saúde, quando comparado com os investimentos realizados no ano de 2014, promovendo a reduções dos níveis de efetividade e eficácia do direito à saúde. Conclusão: o princípio da proibição do retrocesso social pode ser utilizado como instrumento para garantia do direito à saúde, do núcleo essencial do SUS e da preservação das conquistas alcançadas pela sociedade.

Palavras-Chave: Direito à Saúde. Retrocessos Sanitários. Princípio da Proibição do Retrocesso Social. Financiamento para Saúde. Capital Estrangeiro.

ABSTRACT. Introduction: the present article aimed to analyze possible social setbacks from the Constitutional Amendment no 86, of 2015, and the Law $n \circ-13.097$, of 2015. Methodology: it was a quantitative - qualitative research, analytical descriptive, conducted by documental research. Complementarily, literature review was performed on the principle of prohibition of social regression. Results: concluded by the existence of social regression observed in both legislations, since the proposed legislative changes lead to weakening the right to health and the Unified Health System (SUS), especially in

\footnotetext{
1 Advogada. Pós-graduada em Direito Público. Assessora Técnica da Secretaria de Vigilância em Saúde, do Ministério da Saúde (SVS/MS). Brasília, DF. e-mail: kalini.braz@gmail.com.
} 
the aspect of funding that can affect their own sustainability. Regarding the Law no 13.097 , of 2015 , it was verified the regression on the art. 142 , that allowing the direct or indirect participation of the foreign capital in all health assistance activities, even in philanthropic institutions, can provide the expansion of the private sector and the consequent commercialism of the right to health accentuating the inequities on the health system access. About the Constitutional Amendment $\mathrm{n}^{\circ} \mathbf{8 6}$, of 2015, that includes a new base for calculate the federal government application on health, it is verified the social regression by non-observing the progressive character in health investments, when compared to the investments done in 2014, promoting the reduction in effective and efficient levels of the health to right. Conclusion: the principle of prohibition of social regression can be used as an instrument to guarantee the right to health, the essential core of the SUS, and the preservation of the achievements reached by the society.

Keywords: Right to Health. Sanitary Regression. Principle of the Prohibition of the Social Regression. Funding for Health. Foreign Capital.

RESUMEN. Introducción: en este trabajo se propuso examinar los posibles retrocesos sociales derivados de la Enmienda Constitucional (EC) nํ 86 de 2015 y de la Ley $n$ 13.097, de 2015. Metodología: es una pesquisa cuantitativa y cualitativa analítico descriptivo, realizada a través de una investigación documental. De manera complementaria se realizó una revisión de literatura sobre el principio de la prohibición de la regresión social. Resultados: se verificó la existencia de regresión social en los dos textos legales ya que los cambios legislativos propuestos llevan a un debilitamiento del derecho a la salud y del SUS, en el aspecto de la financiación que puede afectar a su propia sostenibilidad. En cuanto la Ley $n^{\circ} 13.097 / 2015$ se produjo un retroceso que, al permitir la participación directa o indirecta del capital extranjero en todas las actividades de atención de la salud, incluso organizaciones benéficas, pueden promover la expansión del sector privado y la comercialización del derecho a la salud que acentúa las desigualdades en el acceso al sistema de salud. Desde la EC no 86/2015, que incluye una nueva base de cálculo para la aplicación del gobierno federal en materia de salud, no es la regresión social por no observar la naturaleza progresiva de las inversiones en salud, en comparación con las inversiones en 2014, reducciones de promoción en los niveles de eficiencia y eficacia del derecho a la salud. Conclusión: el principio de prohibición de la regresión social se puede utilizar como un instrumento para garantizar el derecho a la salud, del núcleo esencial del Sistema Único de Salud y de la preservación de los logros alcanzados por la sociedad.

Palabras-clave: Derecho a la Salud. Contratiempos de la salud. Principio de prohibición del retroceso social. Financiamiento para la Salud y Capital Extranjero.

\section{Introdução}

Após a constitucionalização do direito à saúde, o Brasil vem enfrentando um contexto de crescente insegurança jurídica no âmbito da garantia desse direito. Atualmente existe um aumento das demandas por realização de ações e serviços em saúde frente ao decréscimo da possibilidade prestacional pelo Estado, colocando em 
questão as conquistas sociais já alcançadas. Razões que nos levam necessariamente a debater a aplicação do princípio da proibição do retrocesso como ferramenta para garantir o dever jurídico-constitucional de efetivação do direito à saúde (1).

O Princípio da Proibição do Retrocesso Social é um mecanismo de efetivação e aplicabilidade do direito à saúde. Além disso, consiste no meio de garantia de preservação das conquistas alcançadas pela sociedade ao longo dos anos, ao conter as reduções ou supressões dos níveis de efetividade e eficácia do direito à saúde (1) (2).

Apesar do surgimento de várias obras a respeito do tema nos últimos anos, há um esforço para sistematizar a concretização desse princípio. O Princípio da Proibição do Retrocesso Social ainda não é amplamente difundido, tanto na doutrina quanto na jurisprudência dos tribunais brasileiros.

Entretanto, no direito comparado, esse princípio galgou níveis mais altos de desenvolvimento, a exemplo dos países de larga tradição no direito, como Alemanha (3) Portugal (4) e Itália (5) (6). Oriundo do pensamento jurídico alemão e português e importado pelo Brasil, o Princípio da Proibição do Retrocesso Social tem sua aplicação condicionada às nossas características e peculiaridades socioeconômicas e culturais. Insta salientar que a discussão do Princípio da Proibição do Retrocesso Social é relativamente recente no Brasil.

O primeiro doutrinador brasileiro a abordar a ideia de vedação de retrocesso foi o constitucionalista José Afonso da Silva (7), cujo entendimento das normas que regulam os direitos sociais, incluindo o direito à saúde, define-se como normas programáticas de eficácia limitada, ou seja, necessitam de atuação legiferante por dependerem de norma infraconstitucional para produzirem seus efeitos, constituindo imposição constitucional de atividade legiferante.

Silva (7), sustenta que o legislador fica restrito às imposições constitucionais, de modo que será considera inconstitucional a lei que estabelecer disposição diversa do estabelecido na Constituição. Para Silva (7), lei nova não pode desfazer o grau de efeitos já produzidos e alcançados e ratificados através de lei anterior. Nesse contexto inicia-se a criação do Princípio da Proibição do Retrocesso Social no Brasil, reconhecendo implicitamente a efetividade de tal princípio (7) (8) (9) (10). 
Barroso (9) entende que o Princípio da Proibição do Retrocesso Social consiste em princípio implícito, uma vez que o direito ou garantia instituído constitucionalmente não pode ser arbitrariamente suprimido. Para o autor, "o que se veda é o ataque à efetividade da norma" (9). Assim, fica vedado ao legislador revogar normas regulamentadoras de direito garantido constitucionalmente sem a criação de mecanismo substitutivo.

O reconhecimento implícito do Princípio da Proibição do Retrocesso Social na Constituição decorre dos argumentos presentes no entendimento de alguns princípios como: o Princípio da Dignidade da Pessoa Humana; o Princípio do Estado Democrático e Social de Direito, que por sua vez impõe o mínimo de segurança jurídica para permitir a continuidade da ordem jurídica e a segurança contra medidas retroativas; o princípio da máxima efetividade das normas definidoras de direitos fundamentais; o princípio da proteção da confiança, o qual impõe ao Poder Público o respeito à confiança depositada no Estado para garantir a continuidade da ordem jurídica (8).

Outro argumento que nos permite entender a previsão implícita do Princípio da Proibição do Retrocesso Social consiste na análise de outras normas constitucionais expressamente dedicadas à proteção contra retroatividade, tais como proteção dos direitos adquiridos, do ato jurídico perfeito e da coisa julgada (8).

Além disso, a vinculação às imposições constitucionais a que os órgãos estatais devem atender e a autovinculação em relação a atos praticados anteriormente, também consistem em mais razões para entender a presença implícita do princípio (8).

Divergindo do entendimento dos autores Silva (7), Sarlet (8), Barroso (9) e Derbli (10) que entendem a forma implícita do Princípio da Proibição do Retrocesso Social, Miozzo (11) é um dos poucos autores que sustentam a apresentação desse princípio de forma expressa na Constituição em seu art. 3ํ, II, que estabelece como objetivo fundamental da República Federativa do Brasil, entre outros, a garantia ao desenvolvimento nacional (11).

Outro argumento que permite entender o Princípio da Proibição do Retrocesso Social como explícito, parte da análise do Pacto Internacional de Direitos Econômicos Sociais e Culturais (PIDESC), ratificado pelo Brasil em 12 de dezembro de 1991 e promulgado pelo Decreto Legislativo no 592, de 6 de dezembro de 1992, que em seu 
artigo $2^{\circ}$, prevê, como competência aos Estados-partes, "assegurar progressivamente 0 pleno exercício dos direitos reconhecidos no Pacto por todos os meios apropriados, incluindo em particular por meio de medidas legislativas" (11) (12).

Visto que o Brasil ratificou o referido Pacto, o Estado está positiva e negativamente vinculado à realização plena, à ampliação da cobertura dos direitos econômicos, sociais e culturais e à proteção do direito. Portanto, o Estado possui a obrigação de não regressividade (11). Cumpre salientar que os tratados e convenções internacionais sobre direitos humanos aprovados, em cada Casa do Congresso Nacional, em dois turnos, por três quintos dos votos dos respectivos membros, são equivalentes às emendas constitucionais, conforme disposto no $3^{\circ}$ do art. $5^{\circ}$ da Constituição Federal.

Nesse sentido, o Princípio da Proibição do Retrocesso Social na Constituição Federal pode ser entendido como mecanismo de garantia dos direitos fundamentais sociais, principalmente o direito à saúde, além de garantia dos progressos adquiridos pela sociedade ao longo dos anos, bem como a reduções ou supressões dos níveis de efetividade e eficácia do direito à saúde.

Diante de atuais mudanças legislativas que conduzem a fragilização do direito à saúde e do Sistema Único de Saúde (SUS), colocando em questão sua própria sustentabilidade, o presente estudo analisou textos recentemente sancionados pela Presidente da República: a Emenda Constitucional nº 86, de 17 de março de 2015, (13) e a Lei $\mathrm{n}^{0}$ 13.097, de 2015 (14).

A Lei $n^{0}$ 13.097, de 2015, no art. 142, alterou o art. 23 da Lei $n^{\circ} 8.080$, de 19 de setembro de 1990, permitindo a participação direta ou indireta, incluindo controle, de empresas ou de capital estrangeiro na assistência à saúde, por meio de: a) hospital geral, inclusive filantrópico, hospital especializado, policlínica, clínica geral e clínica especializada; e b) ações e pesquisas de planejamento familiar.

Além disso, permite a participação de capital na assistência à saúde nos casos de: a) doações de organismos internacionais vinculados à Organização das Nações Unidas, de entidades de cooperação técnica e de financiamento e empréstimos; e b) serviços de saúde mantidos, sem finalidade lucrativa, por empresas, para atendimento de seus empregados e dependentes, sem qualquer ônus para a seguridade social. 
O novo texto excluiu o $\S 1^{\circ}$ do art. 23 da Lei $n^{\circ}$ 8.080, de 1990, que estabelecia a obrigatoriedade de autorização do órgão de direção nacional do SUS para doações de organismos internacionais vinculados à Organização das Nações Unidas, de entidades de cooperação técnica e de financiamento e empréstimos.

Ademais, a Lei no 13.097, de 2015, também acrescentou o artigo 53-A à Lei no 8.080, de 1990, apresentando como entendimento de atividades de apoio à assistência à saúde as ações e os serviços desenvolvidos pelos laboratórios de genética humana, produção e fornecimento de medicamentos e produtos para saúde, laboratórios de análises clínicas, anatomia patológica e de diagnóstico por imagem. Dessa forma, fica permitida a participação direta ou indireta de empresas ou de capitais estrangeiros para execução dessas ações e serviços.

A referida lei teve origem na Medida Provisória nํ656, de 7 de outubro de 2014 (15), inicialmente publicada para dispor sobre assuntos tributários e de importação. Entretanto, após análise do Congresso Nacional, foram oferecidas 386 emendas o que acrescentou cerca de cem artigos ao texto.

As emendas fizeram ampliar o conteúdo do texto para os assuntos mais diversos, como: dívidas de clubes esportivos e empresas de radiodifusão, desoneração fiscal, o programa de estímulo à aviação regional, autorização para a construção de um aeroporto privado na região metropolitana de São Paulo, licitação pública, Estatuto do Servidor Público Federal, Agência Nacional de Vigilância Sanitária (Anvisa). Dentre as emendas apresentadas, as de no 99 e 376, de autoria do Deputado Manoel Alves da Silva Júnior (PMDB-PB), previam a abertura ao capital estrangeiro na saúde (16) (17) (18).

Adotada sob a forma de Projeto de Lei de Conversão no 18, de 2014 (19), sancionada como Lei no 13.097, de 19 de janeiro de 2015.

Em janeiro de 2015, com o apoio do governo federal, foi aprovada a Proposta de Emenda Constitucional (PEC) no 358, posteriormente promulgada como a Emenda Constitucional n 86, em 17 de março de 2015, que estabelece uma nova base de cálculo para aplicação mínima em ações e serviços públicos em saúde. A partir do primeiro exercício financeiro subsequente ao da promulgação dessa Emenda serão cumpridos progressivamente pela União os seguintes percentuais da receita Corrente 
Líquida (RCL): 13,2\% em 2016, 13,7\% em 2017, 14,1\% em 2018, 14,5\% em 2019 e $15 \%$ a partir de 2020.

A Emenda Constitucional também estabeleceu a execução orçamentária das emendas parlamentares individuais de forma obrigatória no valor mínimo correspondente a 1,2\% da Receita Corrente Líquida (RCL) da União.

Diante desse panorama, o artigo se propôs a analisar possíveis retrocessos advindos da Emenda Constitucional no 86, de 2015, e da Lei oㅜ 13.097, de 2015.

\section{Metodologia}

Tratou-se de uma pesquisa qualiquantitativa, de caráter descritivo e analítico, na qual resultou a análise documental da Lei oㅜ 13.097, de 19 de janeiro de 2015, e da Emenda Constitucional ํo 86, de 17 de março de 2015. A pesquisa documental foi realizada no sítio eletrônico do Senado Federal, da Câmara dos Deputados e da Presidência da República.

De forma complementar, para aporte teórico, foi realizada revisão narrativa da literatura sobre o tema da aplicação do Princípio da Proibição do Retrocesso Social. Para tanto, foram consultados livros, artigos científicos, teses e dissertações, notas e notícias publicadas pelas entidades ligadas ao movimento sanitário nas bases de dados Scielo, Lilacs, Bireme e Google acadêmico, nos anos de 2011 a 2015, adotando-se os seguintes critérios de inclusão: (a) literatura consultada exclusivamente nacional, de acesso livre e publicada em língua portuguesa; (b) utilização dos descritores: "Princípio da Proibição do Retrocesso Social "; "vedação de retrocesso social", "Princípio da Proibição do Retrocesso Social ", "retrocesso social em saúde", "retrocesso do direito à saúde", "vedação de retrocesso social", "princípio do não retrocesso social", "princípio do não retorno da concretização", "proibição da contrarrevolução social", "retrocesso na Emenda Constitucional no 86, de 2015", e "retrocesso na Lei no 13.097, de 2015"; (c) considerados os textos que abordam o Princípio da Proibição do Retrocesso Social acerca dos direitos fundamentais, de forma geral, bem como aqueles que dispõem especificamente sobre o direito à saúde. 


\section{Resultados}

Da análise da legislação depreendeu-se que houve retrocesso social conforme informações sistematizadas no quadro seguinte:

Quadro 1: Aspectos de retrocesso social encontrados na Lei no 13.097, de 19 de janeiro de 2015, e na Emenda Constitucional oㅡ 86, de 17 de março de 2015

\begin{tabular}{|c|c|c|}
\hline $\begin{array}{l}\text { Norma } \\
\text { Jurídica }\end{array}$ & Matéria normatizada & Aspectos de retrocesso social \\
\hline \multirow{3}{*}{$\begin{array}{l}\text { Lei no } 13.097 \text {, } \\
\text { de } 2015\end{array}$} & $\begin{array}{l}\text { Passou a permitir a participação direta ou } \\
\text { indireta, inclusive controle, de empresas } \\
\text { ou de capital estrangeiro na assistência à } \\
\text { saúde (art. 142) }\end{array}$ & \multirow{2}{*}{$\begin{array}{l}\text { Propicia a expansão do setor } \\
\text { privado e consequente } \\
\text { mercantilização do direito à saúde } \\
\text { acentuando as desigualdades de } \\
\text { acesso aos sistemas de saúde, } \\
\text { desconsidera o núcleo essencial } \\
\text { do SUS (caráter universal, } \\
\text { igualitário e gratuito). }\end{array}$} \\
\hline & $\begin{array}{l}\text { Participação feita por meio de hospitais, } \\
\text { inclusive filantrópicos, clínicas } \\
\text { especializadas e pesquisas de } \\
\text { planejamento familiar (art. 142, I e II) }\end{array}$ & \\
\hline & $\begin{array}{l}\text { Excluiu o } \S 1 \text { do art. } 23 \text { da Lei no } 8.080 \text {, } \\
\text { de } 1990, \text { que estabelecia a } \\
\text { obrigatoriedade de autorização do órgão } \\
\text { de direção nacional do Sistema Único de } \\
\text { Saúde (SUS), para investimento de } \\
\text { capital estrangeiro, submetendo-se a seu } \\
\text { controle as atividades que forem } \\
\text { desenvolvidas e os instrumentos que } \\
\text { forem firmados. }\end{array}$ & $\begin{array}{l}\text { Revogação de } \text { norma } \\
\text { infraconstitucional regulamentando } \\
\text { norma constitucional programática } \\
\text { sem a criação de mecanismo } \\
\text { substitutivo. }\end{array}$ \\
\hline $\begin{array}{l}\text { Emenda } \\
\text { Constitucional } \\
\mathrm{n}^{\circ} \mathrm{86} \text {, de } \\
2015\end{array}$ & $\begin{array}{l}\text { Inclui uma nova base de cálculo para a } \\
\text { aplicação do governo federal na saúde, } \\
\text { executada gradativamente, iniciando no } \\
\text { primeiro exercício financeiro subsequente } \\
\text { ao da promulgação da Emenda em } 13,2 \% \\
\text { da Receita Corrente Líquida, até alcançar } \\
15 \% \text { após cinco anos do exercício } \\
\text { financeiro. }\end{array}$ & $\begin{array}{l}\text { Não observância do caráter } \\
\text { progressivo de investimentos em } \\
\text { saúde, quando comparado com os } \\
\text { investimentos no ano de } 2014 \text {, } \\
\text { promovendo reduções dos níveis } \\
\text { de efetividade e eficácia do direito } \\
\text { à saúde constitucional. }\end{array}$ \\
\hline
\end{tabular}

Fonte: Produzido pela autora com base em análise legislativa.

\section{Discussão}

Com a garantia do direito à saúde previsto constitucionalmente, fruto do movimento sanitário brasileiro, surgiu a necessidade de discutir a sustentabilidade do SUS e o desafio de colocar em prática o seu arcabouço progressista em meio ao momento marcado por crise ideopolítica dos valores progressistas e com o início do 
neoliberalismo e suas políticas de cortes, demissões, privatizações, desestruturação dos serviços de saúde, como corte de investimento, subfinanciamento da saúde, precarização dos vínculos de trabalho no setor público; terceirização de parte dos serviços assistenciais e terapêuticos; conformação de um sistema de saúde complementar, capitalização das empresas multinacionais do setor via planos privados de saúde e consequentes retrocessos sociais (20) (21).

Diante desse panorama e tendo em vista os dados apresentados no quadro 1, cabe fazer uma reflexão acerca dos valores de gastos com a saúde e ações adotadas atualmente que propiciam a expansão do setor privado.

Cerca de 3,9\% do PIB é gasto com a saúde (22), quando a Organização Mundial de Saúde preconiza o valor de 5.5\% do PIB com gasto público médio (23). Ao comparar com o gasto público de outros países que têm um sistema público universal (Reino Unido, Canadá, França e Espanha), e apresentam, em média gastos de 8,3\%, verificase o reduzido investimento brasileiro em saúde (24).

Do gasto total com saúde no Brasil, 48,3\% representam gasto público, enquanto $51,7 \%$ gasto privado (25), ou seja, as parcelas das despesas privadas são superiores aos gastos públicos, o que inviabiliza a efetivação de um sistema público universal e evidencia crescente mercantilização do direito à saúde. Cabe destacar que essa inversão nos investimentos dos gastos com a saúde torna-se um empecilho à justiça e à equidade (26).

Além disso, em 2015 o orçamento da saúde teve corte de $R \$ 11,7$ bilhões visando ajustar o baixo crescimento das receitas e o aumento das despesas, (27) e a diminuição dos recursos aplicados anualmente pela União em ações e serviços públicos de saúde, após a promulgação da Emenda Constitucional nº 86, de 2015.

Aliado a esse contexto de subfinanciamento e não progressividade de investimentos em saúde, cabe também destacar as ações que propiciam a expansão do setor privado. Scheffer e Bahia (28), na pesquisa sobre a representação política e interesses particulares na saúde, demonstram indícios de que o apoio financeiro das empresas de planos privados de saúde para as campanhas de candidatos repercute no objeto dos projetos de lei do Legislativo e medidas do Executivo. Fato este que 
configura como mais um obstáculo para a implantação e na sustentabilidade financeira e política do SUS.

Nas eleições de 2014, quarenta empresas financiaram as campanhas da Presidente da República, três governadores, três senadores, 29 deputados federais, 24 deputados estaduais e outros 71 candidatos que não foram eleitos, bem como 23 partidos, totalizando o valor de $\mathrm{R} \$ 54.902 .441,22$ repassados, valor cinco vezes maior do que foi investido no ano de 2010 , quando os planos de saúde doaram $R \$$ 11.834.436,69 (28).

Do financiamento de 2014 direcionado para partidos, $28,73 \%$ dos recursos foram destinados ao Partido dos Trabalhadores (PT), seguido do Partido do Movimento Democrático Brasileiro (PMDB), 25,01\%, e do Partido da Social Democracia Brasileira (PSDB), 22,04\% (28).

Dentre as empresas que financiaram as campanhas destacam-se a Amil ( $R$ \$ 26.327.511,22), o Bradesco Saúde ( $R \$ 14.065 .000,00)$, a Qualicorp ( $R \$ 6.000 .000,00)$ e o grupo Unimed $(R \$ 5.480 .500,00)(28)$.

Os deputados federais e senadores eleitos com financiamentos de campanhas pelas empresas privadas de planos de saúde tendem a apresentar projetos de lei em defesa dos interesses dos planos de saúde e vetar proposituras que contrariam esses interesses (28). Exemplo desse reflexo dos financiamentos de campanhas pelas empresas privadas de planos de saúde foi a aprovação da Lei no 13.097, de 2015, de autoria do Deputado Manoel Alves da Silva Junior (PMDB-PB), que recebeu financiamento no valor de $\mathrm{R} \$ 105.667,66$ da Bradesco Saúde S/A (28).

$O$ financiamento eleitoral é considerado um instrumento legal, no que tange às doações por pessoa física. O grande problema é quando está associado à corrupção ou troca de favores, permitindo o enfraquecimento do SUS e o retrocesso das garantias já alcançadas. Cabe destacar que, conforme decisão proferida pelo Supremo Tribunal Federal (STF), em setembro de 2015, na Ação Direita de Inconstitucionalidade (ADI) no 4.650 , fica proibida a doação de empresas privadas para candidatos (29).

A abertura da oferta de serviços de saúde ao capital estrangeiro, autorizada pela Lei $n^{\circ}$ 13.097, de 2015, consiste em assunto controvertido e por isso a lei foi questionada no âmbito do STF pela Confederação Nacional dos Trabalhadores Liberais 
Universitários Regulamentados (CNTU) na Ação Direta de Inconstitucionalidade (ADI) ํo 5.239 para pedir a suspensão liminar do artigo 142 da referida lei.

Para o autor da proposta, o Deputado Manoel Alves da Silva Júnior, o capital estrangeiro já se encontra presente em outros setores estratégicos do setor de saúde: nas farmácias, operadoras de planos de saúde, na produção de medicamentos e na fabricação de equipamentos, por isso, não se justifica proibir também para hospitais (30).

O parlamentar, em sua justificação à proposta de Emenda ํo 99 à Medida Provisória, alega que os hospitais ainda não dispõem de uma fonte de recursos para a ampliação da sua infraestrutura e dos serviços de assistência, e para isso necessitam de alto investimento de recursos (30). Complementa, alegando que "é notória a dificuldade do SUS de desempenhar suas funções no atendimento da saúde da população, restando, portanto, à iniciativa privada sanar esta deficiência". Afirmando, ainda, que o capital estrangeiro contribui também com "tecnologia, inovações, melhor governança e práticas, tendo como resultado final a entrega de serviços de melhor qualidade para o consumidor" (31).

A Advocacia-Geral da União (AGU), em manifestação proferida na ADI № 5239, sustentou pela constitucionalidade da lei por entender que a iniciativa privada e a livre concorrência são constitucionalmente asseguradas como fundamentos da ordem econômica (artigo 170, caput e inciso IV, da Constituição). E, por isso, materializa a intenção do legislador de recorrer à iniciativa privada como agente complementar de promover a saúde como direito de todos, de acordo com o previsto constitucionalmente (32). Não obstante complementa, justificando que a abertura do capital estrangeiro seria o melhor a ser feito pelo Estado, dentro do que é possível, entendendo que a livre concorrência deve ser buscada como forma de justiça social (33).

A Procuradoria-Geral da República (PGR) segue o mesmo entendimento apresentado pela AGU, complementando que o art. 199 dispõe que a assistência à saúde é livre à iniciativa privada; sendo vedada a participação direta ou indireta de empresas ou capitais estrangeiros na assistência à saúde no País, salvo nos casos previstos em lei. Desse modo, a Constituição permite a participação, desde que devidamente regulamentada em lei (34). 
Sustenta, também, que cabe ao Estado promover a saúde e a assistência a ela em atuação conjunta com o setor privado. O art. 197 da Constituição estabelece que serviços de saúde cabem ao poder público, no entanto, a execução pode ser implementada por pessoa física ou jurídica de direito privado (34).

A PGR ainda afirma que a Lei também não viola o art. 200, I, da Constituição, uma vez que a fiscalização ao controle das ações e dos serviços de saúde trata-se função típica do estado, como medida de polícia sanitária e, por isso, independente da exclusão apresentada no art. 23 da Lei no 8.080, de 1990, o que não afasta a atuação do Estado na fiscalização dos serviços (34).

Cabe destacar que a manifestação do Senado Federal acerca da constitucionalidade da Lei no 13.097, de 2015, na ADI no 5239, corrobora com as manifestações proferidas pela AGU e pela PGR (35).

Por outro lado, as opiniões apresentadas pelas entidades ligadas ao Movimento pela Reforma Sanitária, tais como Centro Brasileiro de Estudos de Saúde (CEBES), Associação Brasileira da Saúde Coletiva (ABRASCO), Associação Brasileira de Economia da Saúde (ABRES), Associação Paulista de Saúde Pública (APSP), Associação do Ministério Público para a Saúde (AMPASA), Associação Brasileira de Saúde Mental (ABRASME), Instituto de Direito Sanitário Aplicado (IDISA) e Conselho Nacional de Saúde (CNS) são diametralmente opostas (18) (36) (37).

Os argumentos contrários à Lei n 13.097, de 2015, defendem que o normativo não observou as disposições contidas na Constituição que por sua vez veda "a participação direta ou indireta de empresas ou capitais estrangeiros na assistência à saúde no País, salvo nos casos previstos em lei" (§ $3^{\circ}$ do art. 199 da Constituição).

A Lei n 8.080, de 1990, excetuava a participação de capital estrangeiro apenas a empréstimos de organismos internacionais, de cooperação técnica ou vinculados às Nações Unidas. Assim, com a alteração proposta na Lei ํㅜ 8.080, de 1990, o legislador transformou em regra o que deveria ser considerada exceção.

Em adição, a Constituição, ao definir que as ações e serviços públicos de saúde como direito de todos e dever do Estado, vedou a participação, direta ou indireta, de empresas ou capitais estrangeiros na assistência à saúde no país, uma vez que traspõe o dever do Estado ao setor privado e pode gerar insegurança sanitária (18). 
As entidades ligadas ao Movimento pela Reforma Sanitária também argumentam que a Lei viola a Constituição Federal ao suprimir o $\S 1^{\circ}$ do art. 23 da Lei $n^{\circ}$ 8.080, de 1990, que previa a "obrigatoriedade de autorização e fiscalização do órgão de direção nacional do SUS quando da participação do capital estrangeiro" (inciso I do art. 200, da CF) (18).

Além das discussões acerca da constitucionalidade da norma, também são apontadas falhas formais na proposição do Projeto de Lei de Conversão № 18, de 2014, uma vez que " a lei não conterá matéria estranha a seu objeto ou a este não vinculada por afinidade, pertinência ou conexão" (art. $7^{\circ}$ inciso II, da Lei Complementar $n^{\circ} 95$, de 1998) (38).

Ainda quanto ao aspecto formal, também contrariou o disposto no art. $4^{\circ}$, $\S 4^{\circ}$, da Resolução $n^{\circ}$ 1, de 2002, do Congresso Nacional, em que é vedada a "apresentação de emendas que versem sobre matéria estranha àquela tratada na Medida Provisória, cabendo ao Presidente da Comissão o seu indeferimento liminar" (39).

Diante de todo o exposto, verifica-se que a decisão pela abertura do sistema de saúde ao capital estrangeiro foi feita sem que suas reais intenções tenham sido claramente apresentadas, e sem que suas consequências tenham sido debatidas no Congresso Nacional ou em espaços de participação social (26).

A defesa do capital estrangeiro consiste em retrocesso social, uma vez que permite a ampliação da participação do setor privado na formulação das políticas de saúde e amplia o mercado privado de forma diversa ao sistema universal, igualitário e único previsto constitucionalmente (26).

Para Bahia (18), a entrada do capital estrangeiro estimula a fragmentação do sistema de saúde, pois os "projetos políticos defendem o SUS no discurso, mas adotam práticas que o desmontam".

Nessa dinâmica, a referida legislação amplia a mercantilização do SUS, em que a saúde se torna um bem valioso, transacionado no mercado. Isso torna o paciente um mero objeto de consumo e faz com que o Estado assuma o papel de financiador de serviços e bens fornecidos por entidades privadas criando, portanto, um verdadeiro panorama mercadológico (40). 
Como agravante, a Lei no 13.097, de 2015, que permite a participação de empresas e do capital estrangeiro, direta ou indiretamente, nas ações e cuidados à saúde, tem-se a constitucionalização do subfinanciamento do SUS por meio da Emenda Constitucional no 86, de 17 de março de 2015, que altera os arts. 165, 166 e 198 da Constituição Federal, resultado da aprovação da Proposta de Emenda Constitucional nº 358, de 2013 (26).

A alteração do financiamento da saúde por parte da União causou a redução do percentual de investimento pela União. Os recursos previstos na Emenda Constitucional são proporcionalmente menores para as ações e os serviços públicos de saúde quando comparado àqueles aplicados em 2014, que representam 14,38\% da Receita Corrente Líquida do ano, ou seja, foram maiores do que o previsto para o primeiro exercício financeiro, que corresponde a $13,2 \%$ da receita corrente líquida no primeiro exercício financeiro subsequente ao da promulgação desta Emenda (41).

Com a Emenda Constitucional ํo 86, de 2015, após cinco anos do exercício financeiro da sua promulgação haverá um incremento no orçamento para a saúde de $\mathrm{R} \$$ 64,2 bilhões (27). O financiamento do SUS apenas começará a obter ganhos a partir de 2018, com a elevação gradual do percentual da receita corrente líquida para 15\% (42). Desse modo, estimam-se perdas financeiras nos anos de 2015 e 2016 entre $R \$ 8,36$ bilhões e $R \$ 15,71$ bilhões (42).

A análise da Emenda Constitucional, quando comparada com a proposta de iniciativa popular apresentada no Projeto de Lei Complementar no 321, de 2013, pelo Movimento Saúde +10 , que defende o repasse no mínimo de $10 \%$ da receita corrente bruta da União para a saúde (o equivalente a 19,3\% em termos de receitas correntes líquidas), verifica-se que somente no primeiro ano o valor a ser acrescido seria de $\mathrm{R} \$$ 46,0 bilhões (22), chegando ao valor de $R \$ 257,1$ bilhões até o ano de 2018 (27) (43).

Cabe destacar que para a apresentação do Projeto de Lei Complementar n 321 , de 2013, foram colhidas 2,2 milhões de assinaturas, 700 mil a mais do que o exigido constitucionalmente (20).

Para Funcia (42), a nova regra de cálculo para apuração do valor da aplicação mínima constitucional favorece o subfinanciamento do SUS o que acarretará na "perda 
parcial de direitos sociais duramente conquistados pela sociedade brasileira, se nada for feito para reverter essa situação".

Diante desse contexto de inversão nos investimentos dos gastos com a saúde, cortes orçamentários, expansão do setor privado e influências das empresas de planos privados de saúde, cabe observar o Princípio da Proibição do Retrocesso Social , a fim de resgatar a necessidade de aumento nos investimentos público para saúde, capaz de assegurar um sistema único de saúde universal e integral, sendo vedada a interpretação restritiva que retire a possibilidade do direito à saúde ser realizado em caráter progressivo.

O progresso é um objetivo fundamental que deve orientar o Estado e, portanto, também existe um dever de não gerar um retrocesso. É nesse sentido que a análise dos textos normativos deve considerar o Princípio da Proibição do Retrocesso Social. Entendendo, então, que o princípio possui status de princípio constitucional fundamental (9).

Sarlet (8), seguindo o mesmo entendimento de Silva (7), afirma que a proibição do retrocesso resulta diretamente do princípio da máxima efetividade dos direitos fundamentais, impondo proteção aos direitos fundamentais contra a atuação do poder de reforma constitucional, do legislador e dos demais órgãos estatais. Tem, portanto, que concretizar os direitos fundamentais, estando impedido de suprimir ou restringir a ponto de invadir o núcleo essencial do direito fundamental ou atentar contra a proporcionalidade.

Reconhecer que os direitos sociais implicam proibição de retrocesso, significa dizer que, uma vez garantido o direito constitucionalmente, este se transforma em direito negativo ou direito de defesa, ficando o Estado vedado de atentar contra tal direito (10).

Para Barroso (10), "uma lei, ao regulamentar um mandamento constitucional, instituir determinado direito, ele se incorpora ao patrimônio jurídico da cidadania e não pode ser absolutamente suprimido".

O Princípio da Proibição do Retrocesso Social, impõe a ideia de avanço social, ao afirmar que sua finalidade consiste em impor ao legislador a observância da concretização progressiva dos direitos fundamentais, de forma a ampliar as condições 
fáticas, jurídicas e orçamentárias e o grau de concretização dos direitos fundamentais sociais (10).

Derbli (10) afirma que a aplicação do Princípio da Proibição do Retrocesso Social visa preservar o núcleo essencial da norma constitucional, como forma de garantir a vigência do direito previamente garantido, proporcionando ao cidadão segurança jurídica.

A jurisprudência de tribunais superiores também tem se pronunciado acerca do assunto. O STF utilizou o Princípio da Proibição do Retrocesso Social de forma explícita no voto proferido pelo ministro Celso de Melo, no Ag. Reg. no Recurso Extraordinário com Agravo n 639.337, ao afirmar que "o Estado, após haver reconhecido os direitos prestacionais, assume o dever não só de torná-los efetivos, mas, também, se obriga, sob pena de transgressão ao texto constitucional, a preservá-los" (44).

Destarte, negar reconhecimento à existência do Princípio da Proibição do Retrocesso Social implica afirmar que, apesar de o legislador estar vinculado aos direitos fundamentais e às normas constitucionais, poderia livremente decidir pela contrariedade às prescrições do Poder Constituinte (10). Assim, o Princípio da Proibição do Retrocesso Social constitui um limite ao legislador, que deverá observar o núcleo essencial dos direitos já constitucionalmente garantidos, sendo inconstitucional qualquer alteração que promova a reversibilidade desses direitos.

Desse modo, o princípio deve ser observado como forma de exigir que o Estado, dentre suas funções do legislar, não pratique atos que retroagem a política de saúde prevista constitucionalmente (11).

No que tange especificamente ao direito à saúde, o Princípio da Proibição do Retrocesso Social deve ser interpretado e aplicado a fim de combater os retrocessos contra o SUS e contribuir para a efetivação do direito à saúde, com todas as suas características asseguradas pela Constituição e pela Lei ํㅜ 8.080, de 1990, de modo a respeitar as expectativas legítimas dos cidadãos (11).

O Princípio da Proibição do Retrocesso Social pode ser interpretado no sentido de garantir o investimento em saúde, principalmente em relação ao aumento de investimento em gastos públicos, para garantir a atuação do SUS além do mínimo 
existencial e obstaculizando a total privatização dos serviços de saúde, a fim de não retroceder os avanços do direito à saúde já garantidos (11).

Em relação ao retrocesso ocasionado pela influência da saúde privada frente à assistência à saúde prestada pelo Estado, ocasionando a mercantilização do direito à saúde, o Princípio da Proibição do Retrocesso Social deve ser aplicado com o intuito de fortalecer a regulação do mercado de saúde privada, a fim de coibir que interesses pessoais e mercadológicos possam prevalecer frente à efetivação do direito à saúde universal garantido constitucionalmente.

Ademais, o princípio deve ser interpretado como instrumento de garantia da segurança jurídica, consolidação da República, da Liberdade e do Estado Social e Democrático de Direito (11).

\section{Considerações Finais}

A conjugação da interpretação do art. 142 da Lei no 13.097, de 2015, com a Emenda Constitucional $\mathrm{n}^{-}$86, de 2015, favorece o enfraquecimento do SUS, acarretando em retrocesso social, pelo fato de reduzir os investimentos de recursos em saúde, sem observar o dever de progressividade, e propiciar o crescimento da participação de grandes conglomerados privados na saúde, afrontando as conquistas alcançadas pela sociedade.

Essas iniciativas de subfinanciamento do SUS e a supressão de barreiras para atuação do capital estrangeiro na assistência à saúde levam a entender o direito à saúde de forma mercantilizada, transformando os cidadãos em clientes, impondo ao SUS condições cada vez mais desfavoráveis à sua legitimidade.

Além disso, tais mudanças legislativas propostas acentuam as desigualdades de acesso aos sistemas de saúde, ou seja, desconsidera o núcleo essencial do SUS (caráter universal, igualitário e gratuito), o que evidencia o retrocesso social no dispositivo legal e, incontestavelmente, a prevalência dos interesses privados do mercado frente aos interesses coletivos da sociedade na efetivação do direito à saúde.

Assim, o Princípio da Proibição do Retrocesso Social pode ser utilizado como instrumento para garantia da efetivação do direito à saúde, conforme previsto na Constituição, ao impor ao legislador o dever de observar a concretização progressiva do 
direito à saúde, de forma a ampliar as condições fáticas, jurídicas e orçamentárias para sua efetivação.

Portanto, com a aplicação do Princípio da Proibição do Retrocesso Social pretende-se que o legislador, ao elaborar os atos normativos, tenha como objetivo não suprimir ou restringir o direito à saúde, ou seja, impede que sejam desconstruídas as garantias já alcançadas pela sociedade. Com efeito, a aplicação do Princípio da Proibição do Retrocesso Social visa garantir a segurança jurídica que permite aos indivíduos confiar na efetivação do direito à saúde pelo Estado.

O Princípio da Proibição do Retrocesso Social não tem o condão de alterar a conjuntura de fragilização do SUS, mas pode ser um importante instrumento de efetivação do Estado Democrático e Social de Direito em nosso país. 


\section{Referências}

1 Cunha JRA. O Princípio da Proibição do Retrocesso Social como Norte para o Desenvolvimento do Direito à Saúde no Brasil. In: Anais do I circuito de Debates Acadêmicos da Conferência de Desenvolvimento do Instituto de Pesquisa Econômica Aplicada (CODE-IPEA), 2011.Brasília. [Acesso em 24 set. 2015]. Disponível em: http://www.ipea.gov.br/code2011/chamada2011/pdf/area8/area8-artigo3.pdf

2 . Crash sanitário: os retrocessos na política de saúde frente à crise econômica e a alternativa de um princípio constitucional. Cadernos Ibero-Americano de Direito Sanitário 2 (2): 23-35, 2013 [Acesso em 24 set 2015]. Disponível em: http://www.cadernos.prodisa.fiocruz.br/index.php/cadernos/article/view/65/110

3 Böckenförde EW. Teoría e Interpretación de los Derechos Fundamentales. BadenBaden: Nomos, 1993.

4 Canotilho JJ. Rever ou Romper com a Constituição Dirigente: Defesa de um Constitucionalismo Moralmente Reflexivo. In Cadernos de Direito Constitucional e Ciência Política, n.15, São Paulo: Revista dos Tribunais, 1998.

5 Pallieri GB. Diritto Constituzionale. Milão: A. Giufrè, 1963.

6 Zagrebelsky G. História y Constitución. Madrid: Trotta, 2011.

7 Silva JAD. Aplicabilidade das Normas Constitucionais. 6aㅗ edição. São Paulo: Malheiros Editores, 2002.

8 Sarlet IW. A eficácia dos direitos fundamentais. Porto Alegre: Livraria dos Advogados, 2007.

9 Barroso IR. O Direito Constitucional e a Efetividade de Suas Normas: Limites e Possibilidade da Constituição Brasileira. 5aㅗ edição. Rio de Janeiro: Renovar, 2001.

10 Derbli F. O Princípio da Proibição do Retrocesso Social na Constituição de 1988. Rio de Janeiro: Renovar, 2007.

11 Miozzo PC. A dupla face do princípio da proibição do retrocesso social e os direitos fundamentas no Brasil: uma análise hermenêutica. Porto Alegre: Verbo Jurídico, 2010.

12 Brasil. Decreto no 591, de 6 de julho de 1992. Atos Internacionais. Pacto Internacional sobre Direitos Econômicos, Sociais e Culturais. Promulgação. Brasília, 7 de jul de 1992. [Acesso em 31 de out de 2015]. Disponível em: http://www.planalto.gov.br/ccivil 03/decreto/1990-1994/D0591.htm 
programação orçamentária que especifica. Brasília. 18. Mar 2015 [Acesso em 24 set 2015]. Disponível em:

http://www.planalto.gov.br/ccivil 03/constituicao/Emendas/Emc/emc86.htm

14 Lei no 13.097, de 19 de janeiro de 2015. Reduz a zero as alíquotas da Contribuição para o PIS/PASEP, da COFINS, da Contribuição para o PIS/PasepImportação e da Cofins-Importação incidentes sobre a receita de vendas e na importação de partes utilizadas em aerogeradores; prorroga os benefícios previstos nas Leis nos 9.250, de 26 de dezembro de 1995; 9.440, de 14 de março de 1997; 10.931, de 2 de agosto de 2004; 11.196, de 21 de novembro de 2005; 12.024, de 27 de agosto de 2009; e 12.375, de 30 de dezembro de 2010; altera o art. 46 da Lei no 12.715, de 17 de setembro de 2012, que dispõe sobre a devolução ao exterior ou a destruição de mercadoria estrangeira cuja importação não seja autorizada; altera as Leis nos 9.430, de 27 de dezembro de 1996, 12.546, de 14 de dezembro de 2011; 12.973, de 13 de maio de 2014; 9.826, de 23 de agosto de 1999; 10.833, de 29 de dezembro de 2003; 10.865, de 30 de abril de 2004; 11.051, de 29 de dezembro de 2004; 11.774, de 17 de setembro de 2008; 10.637, de 30 de dezembro de 2002; 12.249, de 11 de junho de 2010; 10.522, de 19 de julho de 2002; 12.865, de 9 de outubro de 2013; 10.820, de 17 de dezembro de 2003; 6.634, de 2 de maio de 1979; 7.433, de 18 de dezembro de 1985; 11.977, de 7 de julho de 2009; 10.931, de 2 de agosto de 2004; 11.076, de 30 de dezembro de 2004; 9.514, de 20 de novembro de 1997, 9.427, de 26 de dezembro de 1996, 9.074, de 7 de julho de 1995; 12.783, de 11 de janeiro de 2013; 11.943, de 28 de maio de 2009; 10.848, de 15 de março de 2004; 7.565, de 19 de dezembro de 1986; 12.462 , de 4 de agosto de 2011; 9.503, de 23 de setembro de 1997; 11.442, de 5 de janeiro de 2007; 8.666, de 21 de junho de 1993; 9.782, de 26 de janeiro de 1999; 6.360, de 23 de setembro de 1976; 5.991, de 17 de dezembro de 1973; 12.850, de 2 de agosto de 2013, 5.070 , de 7 de julho de 1966; 9.472, de 16 de julho de 1997; 10.480, de 2 de julho de 2002; 8.112, de 11 de dezembro de 1990; 6.530, de 12 de maio de 1978; 5.764, de 16 de dezembro de $1971 ; 8.080$, de 19 de setembro de 1990; 11.079, de 30 de dezembro de 2004; 13.043, de 13 de novembro de 2014; 8.987, de 13 de fevereiro de 1995; 10.925, de 23 de julho de 2004; 12.096, de 24 de novembro de 2009; 11.482, de 31 de maio de 2007; 7.713, de 22 de dezembro de 1988; a Lei Complementar no 123, de 14 de dezembro de 2006; o Decreto-Lei oㅜ 745, de 7 de agosto de 1969; e o Decreto no 70.235, de 6 de março de 1972; revoga dispositivos das Leis $\mathrm{n}^{\circ} \mathrm{s} 4.380$, de 21 de agosto de 1964; 6.360, de 23 de setembro de 1976; 7.789, de 23 de novembro de 1989; 8.666, de 21 de junho de 1993; 9.782, de 26 de janeiro de 1999; 10.150, de 21 de dezembro de 2000; 9.430, de 27 de dezembro de 1996; 12.973, de 13 de maio de 2014; 8.177, de 1으 de março de $1991 ; 10.637$, de 30 de dezembro de 2002; 10.833, de 29 de dezembro de 2003; 10.865, de 30 de abril de 2004; 11.051, de 29 de dezembro de 2004 e 9.514, de 20 de novembro de 1997; e do Decreto-Lei no 3.365, de 21 de junho de 1941; e dá outras providências. Brasília, Diário Oficial da União [Internet]. Brasília. 20 jan 2015 [Acesso em 24 set 2015]. Disponível em: http://www.planalto.gov.br/ccivil 03/ ato2015-2018/2015/lei/L13097.htm.

15 . Medida Provisória ํㅜ 656 de 2014. Reduz a zero as alíquotas da Contribuição para o PIS/PASEP, da COFINS, da Contribuição para o PIS/PasepImportação e da Cofins-Importação incidentes sobre a receita de vendas e na 
importação de partes utilizadas em aerogeradores, prorroga benefícios, altera o art. 46 da Lei no 12.715, de 17 de setembro de 2012, que dispõe sobre a devolução ao exterior ou a destruição de mercadoria estrangeira cuja importação não seja autorizada, e dá outras providências. [Acesso em 17 out 2015]. Disponível em: http://www.planalto.gov.br/ccivil 03/ Ato2011-2014/2014/Mpv/mpv656.htm

16 Stevanim LF. Capital estrangeiro: o perigo arromba a porta da saúde. Radis Comunicação e Saúde. 1 abr 2015 [Acesso em 8 out 2015]. Disponível em: http://www6.ensp.fiocruz.br/radis/revista-radis/151/reportagens/capital-estrangeiro-operigo-arromba-porta-da-saude

17 Associação Brasileira da Saúde Coletiva, Associação Brasileira de Economia da Saúde, Associação Paulista de Saúde Pública, Associação do Ministério Público para a Saúde, Associação Brasileira de Saúde Mental, Centro Brasileiro de Estudos da Saúde, et al. Nota De Entidades. Capital Estrangeiro - Veta Dilma!. Brasil: 2015. [Acesso em 8 out 2015]. Disponível em: http://www.abrasco.org.br/site/2015/01/nota-entidades-capitalestrangeiro-veta-dilma/

18 Brasil. Câmara dos Deputados. Nota Descritiva da Medida Provisória ํㅜ 656, de 2014. [Acesso em 2 nov 2015]. Disponível em: http://www2.camara.leg.br/documentose-pesquisa/publicacoes/estnottec/notas-descritivas-sobre-medidasprovisorias/2014/nota-descritiva-da-medida-provisoria-no-656-de-2014-pelosconsultores-jose-raimundo-baganha-teixeira-pedro-pereira-silva-e-luiz-humbertocavalcante-veiga-1/at_download/arquivo

19 Brasil. Senado Federal. Projeto de Lei de Conversão (CN) no 18, de 2012. Altera a alíquota das contribuições previdenciárias sobre a folha de salários devidas pelas empresas que especifica, institui o Programa de Incentivo à Inovação Tecnológica e Adensamento da Cadeia Produtiva de Veículos Automotores, o Regime Especial de Tributação do Programa Nacional de Banda Larga para Implantação de Redes de Telecomunicações, o Regime Especial de Incentivo a Computadores para Uso Educacional, o Programa Nacional de Apoio à Atenção Oncológica, o Programa Nacional de Apoio à Atenção da Saúde da Pessoa com Deficiência, restabelece o Programa Um Computador por Aluno, altera o Programa de Apoio ao Desenvolvimento Tecnológico da Indústria de Semicondutores, instituído pela Lei no 11.484, de 31 de maio de 2007, e dá outras providências. [Acesso em 17 out 2015]. Disponível em: http://www25.senado.leg.br/web/atividade/materias/-/materia/106352

20 Cunha, JRA. Avanços e Retrocessos do Direito à Saúde no Brasil: Uma Esperança Equilibrista [dissertação]. Brasília: Universidade de Brasília (UnB); 2014.

21 Paim JS. A Reforma Sanitária e o CEBES. Rio de Janeiro: CEBES, 2012.

22 Mendes A. A saúde pública brasileira no contexto da crise do Estado ou do capitalismo? Saúde e Sociedade.2015. [Acesso em 26 out 2015], 24 (1): 66-81. Disponível em: http://www.scielo.br/pdf/sausoc/v24s1/0104-1290-sausoc-24-s100066.pdf 
23 . Análise de conjuntura do financiamento público federal de saúde no Brasil. [Internet]. Movimento Nacional em Defesa da Saúde Pública "Saúde + 10". 14 abr 2015 [Acesso em 26 out 2015]. Disponível em:

http://www.saudemaisdez.org.br/index.php/2012-10-10-19-31-44/analise-deconjuntura/26-analise-de-conjuntura-do-financiamento-publico-federal-de-saude-nobrasil

24 Mendes A, Alexandre J, Weille B. Renúncia fiscal (gasto tributário) em saúde: repercussões sobre o financiamento do SUS. Revista Saúde e Debate. 2015 [Acesso em 26 out 2015]. 39 (105):491-505. Disponível em: http://www.scielo.br/pdf/sdeb/v39n105/0103-1104-sdeb-39-105-00491.pdf

25 Levi ML, Mendes A. Gasto Total com Saúde no Brasil: a importância e o esforço de medi-lo. Associação Brasileira da Saúde Coletiva. 24 maio 2015. [Acesso em 26 out 2015]. Disponível em: http://www.abrasco.org.br/site/wpcontent/uploads/2015/06/Domingueira-da-Sa\%C3\%BAde-008-2015-24-05-2015.pdf

26 Scheffer M. O capital estrangeiro e a privatização do sistema de saúde brasileiro. Cadernos de Saúde Pública. 2015 [Acesso em 26 out 2015], 31(4):663-666. Disponível em: http://www.scielosp.org/pdf/csp/v31n4/0102-311X-csp-31-04-00663.pdf

27 Villaverde J. Governo Federal anuncia corte recorde no orçamento e freia investimento no PAC. Estadão. 22 maio 2015 [Acesso em 26 out 2015]. Disponível em: http://politica.estadao.com.br/noticias/geral,governo-federal-anuncia-corte-recorde-noorcamento-e-freia-investimentos-do-pac, 1692585

28 Scheffer M, Bahia L.[Relatório de Pesquisa]. Representação política e interesses particulares na saúde: A participação de empresas de planos de saúde no financiamento de campanhas eleitorais em 2014. Rio de Janeiro: Abrasco, 2015.

29 Brasil. Supremo Tribunal Federal. Ação Direta de Inconstitucionalidade (ADI) n 4650. Análise acerca da inconstitucionalidade do art. 142 da Lei no 13. 097, de 19 de janeiro de 2015. Brasília, 5 set 2011 [Acesso em 14 de nov de 2015]. Disponível em: http://www.stf.jus.br/portal/processo/verProcessoAndamento.asp?numero=4650\&classe $=\mathrm{ADI} \&$ origem $=\mathrm{AP} \&$ recurso $=0$ \&tipoJulgamento $=\mathrm{M}$

30 Brasil. Senado Federal. Justificação à Emenda apresentada pelo Deputado Manuel Junior na Medida Provisória no 656/2014. Brasília. 14 out 2014. [Acesso em 2 nov 2015]. Disponível em: http://www.senado.gov.br/atividade/materia/getTexto.asp?t=155082

31 Manoel Júnior J. Câmara vai votar abertura do setor hospitalar para capital externo. Câmara Legislativa. 15 dez 2014. [Acesso em 2 nov 2015]. Disponível em: http://www2.camara.leg.br/camaranoticias/noticias/SAUDE/479458-CAMARA-VAIVOTAR-ABERTURA-DO-SETOR-HOSPITALAR-PARA-CAPITAL-EXTERNO.html 
32 Brasil. Advocacia Geral da União. Parecer da Advocacia-Geral da União acerca da Ação Direta de Inconstitucionalidade no 539. Brasília, 22 maio 2015. [Acesso em 2 de nov de 2015]. Disponível em:

http://redir.stf.jus.br/paginadorpub/paginador.jsp?docTP=TP\&doclD=8557692\&ad=s\#23 $\% 20-$

\%20Peti\%E7\%E3o\%20de\%20apresenta\%E7\%E30\%20de\%20manifesta\%E7\%E30\%20\%20Peti\%E7\%E3o\%20de\%20apresenta\%E7\%E30\%20de\%20manifesta\%E7\%E30\%20 1

33 Advocacia-Geral da União. Mensagem no 121 da Advocacia -Geral da União acerca da Ação Direta de Inconstitucionalidade no 539. Brasília, 20 abr 2015. [Acesso em 2 de nov de 2015]. Disponível em: http://redir.stf.jus.br/paginadorpub/paginador.jsp?docTP=TP\&doclD=8333728\&ad=s\#19 \%20-\%20Presta\%E7\%E30\%20de\%20informa\%E7\%F5es\%20\%20Presta\%E7\%E3o\%20de\%20informa\%E7\%F5es\%201

34 . Procuradoria-Geral da União. Parecer no 221.959/2015-

AsJConst/SAJ/PGR da Procuradoria-Geral da República acerca da Ação Direta de Inconstitucionalidade oㅜ 539. Brasília, 21 out 2015. [Acesso em 2 de nov de 2015]. Disponível em:

http://redir.stf.jus.br/paginadorpub/paginador.jsp?docTP=TP\&doclD=9661925\&ad=s\#29 \%20-\%20Manifesta\%E7\%E30\%20da\%20PGR\%20-

\%20Pe\%E7a\%20recebida\%20pelo\%20webservice\%20Integradorws

35 Senado Federal. Ofício no 066/2015-PRESID/ADVOSF, da Advocacia do Senado Federal acerca da Ação Direta de Inconstitucionalidade nํ 539. Brasília, 13 maio 2015. [Acesso em 2 de nov de 2015]. Disponível em:http://redir.stf.jus.br/paginadorpub/paginador.jsp?docTP=TP\&doclD=8479007\&ad=s\# 21\%20-\%20Presta\%E7\%E30\%20de\%20informa\%E7\%F5es\%20\%20Presta\%E7\%E3o\%20de\%20informa\%E7\%F5es\%201

36 Associação Brasileira de Saúde Coletiva, Associação Brasileira de Economia da Saúde, Associação Nacional do Ministério Público de Defesa da Saúde, Associação Paulista de Saúde Pública, Centro Brasileiro de Estudos em Saúde, Instituto de Direito Sanitário, et al. Movimento da Reforma Sanitária se reúne com Ministro Miguel Rosseto. Centro Brasileiro de Estudos de Saúde. 31 mar 2015 [Acesso em 4 out 2015]. Disponível em: http://cebes.org.br/2015/03/movimento-da-reforma-sanitaria-se-reunecom-ministro-miguel-rosseto/

37 Centro Brasileiro de Estudos de Saúde. Manifesto do Centro Brasileiro de Estudos de Saúde em defesa do direito universal à saúde - saúde é direito e não negócio. Brasil: 2014. [Acesso em 4 out 2015]. Disponível em: http://cebes.org.br/site/wpcontent/uploads/2014/09/Manifesto_Cebes_Sa\%C3\%BAde_\%C3\%A9_direito_e_n\%C3 \%A3o_neg\%C3\%B3cio.pdf

38 Brasil. Lei Complementar no 95, de 26 de fevereiro de 1998. Dispõe sobre a elaboração, a redação, a alteração e a consolidação das leis, conforme determina o 
parágrafo único do art. 59 da Constituição Federal, e estabelece normas para a consolidação dos atos normativos que menciona. Brasília, 27 fev 1998 [Acesso em 4 out 2015]. Disponível em: http://www.planalto.gov.br/ccivil_03/leis/lcp/lcp95.htm

39 . Câmara dos Deputados. Resolução no 1, de 8 de maio de 2002. Dispõe sobre a apreciação, pelo Congresso Nacional, das Medidas Provisórias a que se refere o art. 62 da Constituição Federal, e dá outras providências. Brasília, 9 maio 2002 [Acesso em 4 out 2015]. Disponível em: http://www2.camara.leg.br/legin/fed/rescon/2002/resolucao-1-8-maio-2002-497942normaatualizada-pl.html

40 Nunes JA. Saúde, direito à saúde e justiça sanitária. Revista Crítica de Ciências Sociais. 2009 [Acesso em 27 maio 2015], 87:143-169. Disponível em: http://rccs.revues.org/1588

41 Seminário CNS/COFIN NO 11ํㅡㄹ Congresso da Associação Brasileira de Saúde Coletiva, 28 jul a 1 ago 2015, Goiânia. Goiânia: ABRASCO, 2015.

42 Funcia F. Implicações da Emenda Constitucional no 86/2015 para o processo de financiamento do Sistema Único de Saúde. Revista Consesus. 2015. [Acesso em 26 set 2015]. 15. Disponível em: http://www.conass.org.br/consensus/implicacoes-da-emendaconstitucional-n-862015-para-o-processo-de-financiamento-sistema-unico-de-saude/

43 Conselho Nacional de Saúde. Nem Menos e Nem Depois: 10\% Já! Brasil: 2013. [Acesso em 26 out 2015]. Disponível em:

http://www.saudemaisdez.org.br/index.php/2012-10-10-19-31-44/90-nem-menos-e-nemdepois-10-ja-diz-conselho-nacional-de-saude

44 Brasil. Supremo Tribunal Federal. Ag. Reg. No Recurso Extraordinário com Agravo 639.337. Agravante: Município de São Paulo. Agravado: Ministério Público do Estado de São Paulo. Relator: Min. Celso de Mello. Brasília, 23 ago 2011. DJe: 02587 (01): 00125, set, 2011.

\section{Como citar este artigo:}

Braz KV. A aplicabilidade do Princípio da Proibição do Retrocesso Social como meio de garantia constitucional ao direito à saúde. Revista Cadernos Ibero-Americanos de Direito Sanitário. 2016 jan./mar, 5(1):78-101. 